\title{
A concepção Kulina de território: história e política
}

Kulina conception about territory: history and politics

\author{
Genoveva Amorim* \\ *Pesquisadora independente - Manaus, AM, Brasil \\ genovevaamorim@hotmail.com \\ https://orcid.org/0000-0002-3038-7619
}




\title{
Resumo
}

Neste artigo analiso o território Kulina como elemento essencial na elaboração de estratégias políticas e na constituição do grupo étnico. Verifica-se, através de narrativas e processos, como os Kulina reinterpretam e recriam as tradições para enfrentar os desafios na sua relação com a sociedade nacional e globalizada. Apreende-se que a relação com o território é entranhada de carga afetiva e simbólica. E constata-se que as narrativas são formas de acessar a memória para construir o espaço, o tempo e ressignificar as lutas atuais. A chave de interpretação é a concepção de território - como construído e imaginado: local de morada dos humanos e extra-humanos. O território como espaço que mistura o tempo mítico e atual, e mobiliza a defesa dos direitos. Essa análise foi empreendida junto aos Kulina (falantes de uma língua pertencente à família Arawa) na região do Baixo Juruá, no estado do Amazonas.

Palavras-chave: Kulina; território; política; direitos.

\begin{abstract}
In this paper I analyze the Kulina territory as an essential element in the elaboration of political strategies and in the constitution of an ethnic group. Through narratives and processes, we can see how the Kulina reinterpret and recreate traditions to face the challenges in their relationship with national and globalized society. Relationship with the territory is full of affective and symbolic content. Narratives are ways of accessing memory to build space, time and to re-signify current struggles. The key to interpretation is the conception of territory - as constructed and imagined: the dwelling place of humans and extra-humans. The territory as a space that mixes the mythical and current time, and mobilizes the defense of rights. This research was developed with the Kulina (speakers of a language belonging to the Arawa family) in the Lower Rio Juruá region, state of Amazonas, Brazil.
\end{abstract}

Keywords: Kulina; territory; politics; rights. 
O rio Juruá é um grande território Kulina, ${ }^{1}$ espaço de constantes deslocamentos. Através da relação Kulina com o rio Juruá podemos viajar através do tempo e da memória. É a partir dessa relação que pretendo apresentar a concepção Kulina de território: na forma de ocupação, nos marcadores territoriais e na concepção do "lugar bom" para morar.

Para refletir sobre os constantes fluxos migratórios Kulina utilizei como ferramenta a análise processual. Ou seja, busquei entender como as regras, as estratégias e as tradições são manipuladas pelos indivíduos dentro de uma perspectiva de conflito e de transformação social. A noção de processo permite abordar as narrativas históricas como algo que se desenvolve no tempo. Rompe com a ideia de ciclo, e afasta os conceitos evolucionistas, ou a concepção da história com algo natural (que não permite escolhas nem variações). Assim, as narrativas são compreendidas como formas de reconstruir o passado, a partir de uma pergunta feita para responder a uma demanda atual. Instrumentos importantes para obter descrição e análise.

Nesse sentido foi necessário descrever e aprofundar a dinâmica dos processos de territorialização a partir da concepção de território como algo construído, imaginado, como "suporte físico e material de coletividades portadoras de tradições, que elaboram estratégias socioculturais dentro de um marco histórico preciso". ${ }^{2}$ Outra importante ferramenta de análise para a compreensão do processo de territorialização Kulina é a noção de fronteira. Tal postulado - na condição de modelo analítico dos fenômenos histórico-sociais - implica conceber a fronteira como fruto de relações sociais assimétricas. Empreender uma análise a partir da perspectiva de fronteira sugere, portanto, considerar os aspectos econômicos, políticos e sociais, sobretudo no que tange às relações sociais dinamicamente construídas em face das relações de subordinação. Implica também considerar a fronteira como um ato político, ou seja,

1 Os Kulina falam a língua própria que pertence à família linguística Arawa. Também são membros desta família os Banawá, Deni, Jarawara, Kanamanti, Paumari, Suruwaha, Jamamadi Ocidentais, Jamamadi Orientais e possivelmente os isolados Hi Merimã. Os Kulina estão presentes no Peru e nos estados brasileiros do Amazonas e do Acre: no Alto, Médio e Baixo Juruá, e nos rios Jutaí e Purus (Amorim, 2014, p. 2). Esta análise foi desenvolvida a partir de trabalho de campo junto aos Kulina que habitam a região do Baixo Juruá, no estado do Amazonas.

2 Pacheco de Oliveira (2012), na ementa da disciplina Antropologia do Território, PPGAS-UFAM. 
como uma criação de instância política. Dessa forma a noção de fronteira inclui um conjunto de agentes e atividades que relacionam as partes, conectando-as, construindo uma ficção (Pacheco de Oliveira, 1978).

A base de análise é a relação que os Kulina estabelecem com o lugar onde moram ou onde moraram. Relação essa que não é de lucro ou de posse, mas de vínculo com "quem ficou no local". Desenvolvi esta ideia a partir de diálogos mantidos com Tone Kulina, liderança e professor. ${ }^{3}$ Conversando do processo de reocupação do território Juruapuca, ele afirmou:

Tone: Agora era pra gente estar comendo melancia aqui. Mas eles foram embora todinhos. Eu fiquei sozinho. Uma pessoa. Quando a gente foi na cidade e voltou tinham saído. Ainda passamos quase um mês aqui. Eu e o Zé. O Zé foi embora, abandonou a casa dele e eu fiquei sozinho. Passei dois anos sozinho. Eu fui lá com o secretário [de Educação] e disse que eu queria uma escola aqui. Ele me perguntou se fulano estava aqui, se aquele estava... $\mathrm{E}$ eu respondia dizendo que estava.

Bira: Você estava mentindo?

Tone: Mentindo, não! Taí, voltaram tudo de novo. Eu fui lá com o prefeito e falei com ele: "Prefeito, é o seguinte: Madija deram o nome errado, era ter colocado jidsama madija. Era certo." Ele perguntou: “Por que você está dizendo isso?" Eu disse: “Porque eles vão voltar. Você quer apostar?” Ele disse: “Tá bom, vamos apostar!" Ele fez a relação do material para a escola.

Fiquei sozinho. Eu, o serrador e o carpinteiro que estavam fazendo a escola. Depois que fizemos a escola todinha, pintamos todinha, eles chegaram de novo [os Kulina voltaram]. Iam chegando um a um. Pois é, foram embora, demorou um tempo e voltaram de novo pro Jaci [aldeia]. E eu falei para a Funai. Eu disse: "Um tem que morar, porque eles vão embora. Vão comer por ali, morre um ou dois... Se não morre tudo, eles voltam pro mesmo canto."

3 Tone é uma jovem liderança, a mãe é Kulina e o pai não indígena. Ele foi criado pelo seu tio-avô Dimodo Kulina. Desde os anos 1990 Tone demostrou interesse em conhecer os territórios Kulina, em aprender a ler e a escrever em língua Kulina e em português. Liderou a retomada do território Juruapuca, atua como intérprete e como diplomata em atenção às demandas gerais dos Kulina na cidade. Recentemente trabalha na coordenação escolar indígena do município de Juruá. 
Por isso que eu morro aqui, não saio daqui, não. Se eles quiserem ir embora, vão embora. Foi por isso que eu disse também que esse negócio de chamar Kulina, não era pra ter colocado Kulina, não. Era pra ter colocado ou jidsama madija [queixada madija] ou abaridsa madija [urubu madija], um dos dois. Porque se ficar um pra trás, eles voltam. ${ }^{4}$ (Conversa gravada na casa do Tone na aldeia Boca do Jaci, dezembro de 2015).

Para um Kulina um território nunca é abandonado. Um Kulina vivo pode viajar, mas no território ficam os mortos, as plantas cultivadas e os seres extra-humanos, como o rami. Um Kulina vivo sempre retorna a esses territórios. Não dá para os Kulina abrirem mão desses locais, pois abrir mão desses territórios é abrir mão do vínculo. Todos podem ir embora, mas se uma pessoa ficar, um dia os outros voltam. Retornam atrás daquele que ficou: "somos jidsama madija" ("somos queixada madija"). ${ }^{5}$

A análise parte da reocupação do território Juruapuca no intuito de se aproximar da concepção de território Kulina. O que denomino território Juruapuca é uma faixa de terra localizada próxima à cidade de Juruá (distante duas horas da sede do município, em um motor rabeta 5 hp). Logo ao entrarmos no território Juruapuca nos deparamos com o lago Juruapuca, antigo lago de uso Kulina. ${ }^{6}$ O território está localizado abaixo da cidade de Juruá e o acesso é pela foz do igarapé Branco (margem direita do rio Juruá). Recentemente o território Juruapuca passou a fazer parte da Reserva Extrativista do Baixo Juruá - Resex Baixo Juruá.7

4 Na aldeia Boca do Jaci habitam aproximadamente 78 pessoas.

5 Utilizarei o termo "Kulina" fazendo referência à etnia, porém saliento que a autodenominação de todos os Kulina é Madija. Por isso algumas vezes o termo "Madija" aparecerá fazendo referência à etnia Kulina, no caso o mesmo aparecerá escrito com letra maiúscula (este será o procedimento que utilizarei nas narrativas, conversas e transcrições de vídeos para respeitar a "fala" dos sujeitos). Utilizarei o termo madija - escrito com letra minúscula e em itálico - quando estiver fazendo referência aos subgrupos (por exemplo: jidsama madija: queixada madija). Os subgrupos madija são unidades sociais ou "tipos de gente" "nomeados a partir de alguma espécie animal ou vegetal" (Gordon, 2006, p. 86).

6 Há registros da presença Kulina, no local, de 1974 até o final do ano de 1989 em Soares e Mochiizawa (1997).

7 A Reserva Extrativista do Baixo Juruá foi reconhecida no dia $1^{\circ}$ de agosto de 2001, possui 187.980,70 hectares e está localizada nos municípios de Juruá (AM) e Uarini (AM). 
A seguir apresento um relato sobre a saída dos Kulina da aldeia Mapiranga, ${ }^{8}$ a ida a cidade de Juruá e a reocupação do território Juruapuca:

Huaido: ${ }^{9}$ Primeiro foi o Tone que veio para cá [que comprou casa na cidade]. Ele veio em 2009. Primeiro veio o Tone, a mamãe e o irmão dele.

Tone: Em 2002 nós chegamos lá no Juruapuca. Era eu, Joppino,, Joji e Dimodo Velho, éramos quatro. Jodsino ficou no Mapiranga. Huaido estava também. Nós saímos do Mapiranga depois que o Joppino adoeceu. Nesses dias que nós começamos a ver o que era viver na cidade. Nós passamos cinco dias do Mapiranga pra cá, remando. Lá no Botafogo [comunidade não indígena que fica às margens do rio Juruá] o vovô Dimodo tinha um cachorro chamado Huesseno. Quando ele pulou assim no seco, Huaido falou: "Não sei por que o papai gosta de cachorro." Dimodo ficou com raiva. Ele pulou na popa da canoa, remou, remou que a canoa rodou e disse: "Agora nós vamos baixar aqui mesmo. Não vamos mais pro Juruapuca." Toda a zanga por causa do cachorro dele. Nós embarcarmos o cachorro dele e viemos embora. Ah! Com esse cachorro nós matamos muita paca aí. Todo dia nós matávamos duas ou três. Nós viemos embora do Mapiranga por causa de huima dori [fofoca]. Jodsino não veio porque ele ficou morando de uma aldeia pra outra, por isso que ele tem casa aqui, no Mapiranga, no Matatibem [aldeia]. Nós só vivíamos pescando pra lá e pra cá. Me deram a notícia que o Rohuidsi e o Corari vinham me buscar. Eu fui embora de novo [voltou para a aldeia Mapiranga].

8 A aldeia Mapiranga está localizada dentro da Terra Indígena Kumaru do Lago Ualá, em Juruá.

9 Huaido (filha de Dimodo) é uma das lideranças na retomada do território Juruapuca. Trabalhou como professora e atua como intérprete na cidade de Juruá. É respeitada na cidade pelos não indígenas e pelos Kulina. Por sua fluência em português é uma defensora dos Kulina na sua relação diária com os não indígenas. Possui capacidade de agregar Kulina ao seu redor. É a primeira moradora Kulina no bairro Tancredo Neves II, na cidade de Juruá. A concepção de território Kulina não nos permite reduzi-los ou enquadrá-los na classificação corrente de "índios na cidade", pois os Kulina extrapolam todas essas denominações generalizantes com suas múltiplas possibilidades de morar. Dessa forma a contribuição antropológica que mais se aproxima dessa realidade são os conceitos de etnografia multissituada de Marcus (2001). A etnografia multissituada tem como finalidade apresentar o "objeto de estudo" como uma formação cultural produzida a partir de diferentes locais. Assim, a investigação etnográfica se dá através da junção de múltiplos lugares em um mesmo contexto de estudo, no qual o sujeito é móvel e múltiplo. Quer dizer, não existe o "sujeito situado" e subalterno (Marcus, 2001, p. 113-115).

10 O nome indica uma família extensa e sua rede de agregados políticos. 
Fui com o secretário, falei com ele e com o prefeito, eles me contrataram, e melhorou [contrataram Tone para trabalhar como professor na aldeia Mapiranga]. Tinha 35 famílias no Mapiranga. Compraram motor de luz. Era 2004, por aí. Dimodo também voltou. Eles me contrataram em janeiro de 2005. Eu falei com o prefeito e levamos tudo pra instalar na casa de energia, ficou bonito lá. Eu passei bem uns quatro anos lá.

Depois eu vim embora pra cidade. ${ }^{11} \mathrm{O}$ pai dele [pai do Zé, esposo da Huaido] disse que tinha essa terra aqui [no Jaci]. Ele não tinha como morar aqui. Em janeiro de 2009 nós viemos pra cá [para a aldeia Boca do Jaci]. Fizemos um tapiri bem aqui. De tarde nós matamos macaco e nós comemos. Nós roçamos até por aqui. Aqui tinha muito açaí.

Depois o Joppino veio, viu que eu estava aqui. Aqui tinha muito açaí, açaí da natureza mesmo. Boca do Jaci é nome antigo do lugar. Madija já cortava seringa por aqui. Aquiridso [irmão do Tone] nasceu pra cá pra dentro do Juruapuca [há muito tempo].

Eu e Evilázio fizemos um roçado grande ali pra dentro. Tinha muita madeira. Chegou Joppino, depois chegou Dsoho, Bena, Bidajari e Sico, lá do Xeruã. Chegaram também Comino e Davi. Depois plantamos todo o roçado. Fizemos outro roçado, foi que Jodsino chegou, depois de dois anos.

Depois chegou Coni e Rohuidsi. Rohuidsi fez casa onde está hoje a casa do Jodsino. Plantou aqui e voltou pra lá de novo [para a aldeia Mapiranga]. Camu também já morou aqui com a Sidae. Ahuano que não veio, diz que morre, mas não abandona o Mapiranga.

Huaido: Eu tenho vontade de morar no Mapiranga. Lá tem muita fartura [peixe], mas as pessoas não gostam de Madija casado com branco.

Tone: Foi por isso que eu saí. (Conversa gravada na casa da Huaido na aldeia Boca do Jaci, 4 de outubro de 2016).

11 É necessário verificar aqui a forma como os Kulina se identificam como tais a partir de um território que é imaginado, mas também concreto: a aldeia e a cidade (aldeia e cidade compreendidas não como polos opostos e contraditórios, mas como partes de um mesmo processo). Dentro dessa concepção, a etnicidade e os habitantes (do território) são transitórios. É esse princípio processual que nos permite compreender o "jeito de morar" dos Kulina e captar o momento social no qual as pessoas circulam, isto é: encontrar a aldeia dentro da cidade. Porém, vale ressaltar que esse empreendimento só é possível se dissolvermos nossa concepção de aldeia, de cidade e de cultura. 
Por volta do ano 2002, os Kulina começaram o processo de retomada do território Juruapuca construindo casas e fazendo roçados, porém foram expulsos do local. De acordo com seus depoimentos, foram convencidos a se retirar por uma equipe formada por membros da Fundação Nacional do Índio (Funai) e do Instituto Chico Mendes de Conservação da Biodiversidade (ICMBio). Contudo, eles não desistiram, e, após uma série de resistências e negociações, em 2009 conseguiram fazer uma aldeia próxima ao antigo local, no lugar denominado Boca do Jaci - uma antiga "colocação" da família de José Amorim (conhecido como Zé, esposo de Huaido).

Dessa forma a presença Kulina foi tolerada na área onde está situada a aldeia Boca do Jaci, localizada às margens do igarapé Jaci. Mas foi negado o acesso aos Kulina a todo o território de antiga ocupação, no qual estão localizados seus antigos roçados, suas plantas frutíferas e ritualísticas (como o arbusto utilizado no ritual do rami $^{12}$ ) e seus cemitérios. É importante frisar que a aldeia Boca do Jaci - bem como o uso Kulina de todo o território - não é reconhecida pelo órgão gestor nem pelas comunidades não indígenas da Resex Baixo Juruá.

A volta dos vivos ao território Juruapuca: violência e enfrentamento

Huaido: Aquela mulher morreu?

Tone: Não, mas ela pegou a conta [foi demitida].

Zé: Negócio de expor os Madija em foto. Ela tinha que pedir autorização.

Eu: Ela fez montagem?

12 Ritual Kulina na qual os mesmos ingerem o chá alucinógeno que ficou conhecido como ayahuasca. Em minha dissertação encontra-se uma descrição desse ritual (Amorim, 2014). Pollock (1985) foi o primeiro pesquisador a estudar a importância do rami para os Kulina: a relação entre o pajé, o feitiço das folhas e a cura. Observou o uso de folhas para atrair o sexo oposto e para curar, bem como o uso do chá ayahuasca. $O$ autor apontou uma diferença entre o rapé e a ayahuasca como produtores de visões e miragens (viagens). Assim, de acordo com esse pesquisador, os pajés usam rapé de tabaco para ver o submundo (ou mundo subterrâneo: nami bodi) e interagir com os espíritos tocorime. As visões induzidas pelo tabaco são restritas a eventos espaçotemporais das aldeias e áreas adjacentes, enquanto que as visões da ayahuasca são de outros lugares, outras aldeias, outras cidades, ou mesmo outras terras. Essas visões também podem ser de eventos futuros, que são colocados em movimento a partir das visões do dsamarini passo (o patamar das águas), território criado e habitado pelo herói mitológico Kira. 
Tone: Foi, ela fez. Uma foto [montagem] dos Madija com um monte de madeira e eu fiquei segurando um litro de 51 na mão.

Huaido: A gente não tem nem motosserra. E então [aparece] o motosserra e um monte de madeira com o Tone em cima.

Tone: Ela tirou uma foto minha em pé, conversando, né? O Rocha da Funai veio e acabou com tudo. Foi assim que a gente voltou pro Juruapuca, o pessoal do Ibama [ICMBio] falou pra gente sair. Depois de tudo isso teve ainda tiroteio, lá no roçado. No outro dia me chamaram para ir falar com o juiz. Nesse dia ele chegou, e eu disse: "Vá embora, não tenho medo, não! A gente não vai preso, não!" Esse Rocha da Funai foi conosco. Até o sargento está ainda, ele ficou com o olho desse tamanho. Nós estamos de banda, nós dois. Outro dia eu fui lá de novo e ele ficou me olhando. De quando os policiais foram no Jaci e nós os colocamos pra correr. Foram lá brigar com a gente. Nós estávamos na nossa terra mesmo, plantando, e não estávamos fazendo nada de errado.

Eu: Por que eles foram pra lá?

Tone: Porque nos denunciaram. Não queriam que a gente morasse lá. Não queriam que a gente ficasse próximo da reserva [Resex Baixo Juruá]. Denunciaram e a polícia foi lá. Eram oito. Polícia daqui mesmo que foi. (Conversa gravada na casa da Huaido, cidade de Juruá, outubro de 2016).

A aldeia Boca do Jaci contempla em parte a falta do antigo território, mas os Kulina falam da ausência do território Juruapuca e de como foram expulsos do mesmo: após sua saída do território Juruapuca no final de 1989 (para morarem na TI Kumaru do Lago Ualá), os não indígenas passaram a ocupar o local. Contam como um arbusto usado no chá do rami (Psychotria viridis) protegeu o local de invasores, e resistiu todos esses anos. O arbusto de rami era cortado constantemente pelos não indígenas e brotava novamente. Próximo ao local onde o arbusto está plantado e nas casas apareciam seres estranhos, crianças e adultos adoeciam constantemente.

O rami mora, protege e demarca o território

Ahuano: Eu plantei rami lá no Mapiranga [aldeia]. Ele é meu, se eu sair de lá ninguém mais vai morar lá.

Tone: Eu dei pra ele.

Ahuano: Toda hora assobia detrás de minha casa. 
Tone: Ali no Juruapuca nós dormimos. Nós éramos oito homens. De noite "Madija" cantava como se fosse o Rohuidsi [pajé] cantando atrás da casa. Passou a noite todinha, cantando cantos do rami.

Huaido: O Louro [não indígena], que morava no Juruapuca, teve que sair de lá porque a mulher só vivia assombrada. Abandonaram. Eles contam que ouviam conversa ao redor da casa, perto da parede, jogava pedra. A mulher ficava doida, tiveram que sair.

Tone: Eu falei no dia que eu fui a casa dele: "Seu Louro, se você quiser tua mulher viva, sai do Juruapuca e deixa pra nós. Pelo menos nós cuidamos das plantas que têm lá." Ele disse: "Eu vou matar tudo."

O Louro foi lá e meteu a roçadeira. Matou tudinho, tudinho [as plantas]. Sim, ele passou a roçadeira também no nosso rami. A mulher dele ficou doida mesmo. Foi pro médico, e não dava era nada [fazia exame e não descobria a doença]. Até hoje ainda ela é doente. Deoclésio, que é rezador, disse que rezou, e viu que se ela voltasse para lá eles [o rami] iriam sumir com ela. O Louro ficou doido e tocou fogo na casa dele mesmo, nem arrancou [nem aproveitou o material].

Os dsoppineje [pajés Kulina] que vão falar com eles [rami] dizem que eles só querem Madija lá. Não querem branco, não! Os dsoppineje contaram que ele [rami] tem quatro braços: um aqui, outro aqui, dois olhos pra cá e outro pra cá, dois olhos na frente e dois atrás. Dseca [pajé] disse que ele é feio.

Dseca não tem vergonha, não! Ele conta mesmo. Ele disse, no dia que nós fomos pescar. Ele disse que tinha uma cabeça torada [cortada] bem aqui [no pescoço]. Só a cabeça falando com ele, que ele ficou com medo. Eu disse: "Tu tá mentindo." Ele disse: "Se tu fosse dsoppineje [pajé] eu ia te levar pra ver, tá bem ali, cabeça falando sozinha."

Por isso que se eu me tornasse pajé, lá pelo Jutaí [iniciado na aldeia Batedor, no rio Jutaí] ia dizer pra eles [rami] dar paulada em branco que entrasse no Juruapuca. Ia fazer eles ficar doido. Isso é coisa do rami mesmo, querer que o cara fique doido. (Conversa gravada na casa da Huaido, cidade de Juruá, outubro de 2016).

Uma pessoa ao chegar ao território Juruapuca, ao avistar algumas palmeiras de açaí e capoeiras recentes, poderá identificar o local como território não indígena. Mas um Kulina é capaz de identificar, em toda aquela floresta e capoeiras: plantas de pomar, cemitérios (onde estão sepultados seus avós e pais), roçados antigos e, principalmente, o local onde está plantado o rami. 
Os Kulina são capazes de identificar todos os que foram plantados no local: pessoas, plantas e extra-humanos. Saliento aqui a estreita relação entre cemitérios e roçados, visto que o roçado é o local privilegiado de sepultamentos. Nesse sentido o termo ppanade significa plantar e também sepultar, em língua Kulina.

É importante perceber como a memória constrói o espaço e o tempo. ${ }^{13}$ Uma memória que é individual, mas é ao mesmo tempo coletiva, e diferente da memória oficial do Estado e de seus agentes. Os Kulina retornam ao tempo de seu avô para legitimar ou buscar explicações para os desafios e questionamentos que são colocados hoje. O rami, como planta, traz a "temporalidade de parentesco", ${ }^{14}$ pois os Kulina são capazes de identificar quem plantou (foi o avô ou o pai de fulano). Conectam o tempo antigo - o tempo do avô - com o tempo atual, e dessa forma estabelecem vínculo com o território, impregnado de carga afetiva. Ou seja, os vínculos, as histórias de vida e a presença de seres extra-humanos demarcam território. ${ }^{15}$ Um território no qual o rami e o cemitério constituem um grande roçado. ${ }^{16}$

13 Schiel (2004), ao desenvolver uma investigação sobre o passado, a memória e a história do povo Apurinã através de narrativas orais, percebeu como esse ato implica a existência de uma noção de um tempo passado que tem importância política atualmente A pesquisadora concluiu que a memória, que se constrói no espaço, era algo constante em todas as histórias: "O passado se conta com referências a outros espaços. As colocações, os caminhos, as árvores, trazem a marca do que já foi" (Schiel, 2004, p. 158).

14 Referências a partir de anotações feitas por mim durante seminário ministrado por Joana Cabral de Oliveira: “Temporalidades vegetais", Neai (Núcleo de Estudos da Amazônia Indígena), PPGAS/UFAM, 20 de maio de 2016. "Esse singelo episódio mostra não só o afeto em relação a alguns cultivares, como também as relações de parentesco que se depositam nesses espécimes - afinal aquele pé de algodão tapupura havia sido um presente materno" (Cabral de Oliveira, 2016, p. 119).

15 "Contar dos Makonawa é reconstruir a memória do Cujubim, da sua moradia, em função do conflito presente e afirmando a presença indígena. A presença dos Makonawa se percebe através das fruteiras, - açaizeiro, pupunheira, mangueira, etc. - que Pedro Rafael me contou terem sido plantadas por eles, e das almas, 'curupiras', insistiram muito tempo em assombrar. Foi Palmira, mãe de Antônia, mulher de Chicão, que 'ajeitou' o lugar. Ainda que não trabalhe 'chupando' as pedras de doenças, Palmira trabalha em sonho. Ajeitar lugares assombrados é uma das coisas importantes que um pajé tem que fazer" (Schiel, 2004, p. 319).

16 Silva (1997, p. 21) analisou a relação entre cosmografia e cosmologia a partir da ocupação dos espaços por humanos, animais, espíritos e plantas; estudo realizado entre os Kulina da aldeia Santa Júlia, no estado do Acre. 
Os Kulina estão chamando de modo jocoso a Jodsino Kulina de tossipa madija (jacamim madija), porque depois que seu pai, Dimodo, morreu, ele permaneceu em constante movimentação. Jodsino tem casas e roçados na aldeia Matatibem (rio Eré, Carauari), na cidade de Juruá, na aldeia Boca do Jaci e na aldeia Mapiranga (TI Kumaru). Participa de cursos de formação de lideranças e de professores Kulina desde os anos 1980, promovidos pelo Conselho Indigenista Missionário (Cimi). Nos anos de 1997 a 2001 Jodsino era tuxaua da aldeia Mapiranga e exercia grande liderança entre os Kulina no Baixo Juruá. Em 2001 atuava como agente indígena de saúde e como membro do Conselho Distrital de Saúde Indígena do Médio Rio Solimões e Afluentes - CONDISI-DSEI-MRSA. Nos últimos anos Jodsino tem ocupado posição de professor nas aldeias Boca do Jaci (território Juruapuca), Morada Nova e Mapiranga.

Contaram-me que logo que Dimodo faleceu, Jodsino viajou sozinho para Carauari, deixando na aldeia Mapiranga a esposa e os filhos. Como eles possuíam um grande roçado, a esposa e os filhos ficaram na aldeia, fazendo farinha e pescando. Jodsino retornou quase um ano depois. As pessoas relacionam esse comportamento também com um episódio que envolveu a caça a um macaco-preto. Eles contam que Jodsino estava caçando e atirou em um macaco-preto. O macaco-preto caiu em cima dele e houve um choque contundente de cabeças. Como consequência do acidente, "os olhos dele ficaram grandes" e passou a ver o mundo deformado. Os Kulina terminaram de matar o macaco-preto e o cortaram em pedaços - forma antiga de pôr fim ao corpo dos pajés assassinados após acusação de feitiço mortal. ${ }^{17}$ Em seguida jogaram fora os pedaços do macaco-preto (não o comeram). Jodsino se recuperou, mas nunca voltou a atirar em macacos-pretos.

17 "Joao, for example, was accused of the witchcraft that killed Katore. On the day of Katore's death Joao was taken into the jungle by a group of men, where he was clubbed to death: his body was thrown into a stream. During the week or so following the deaths, Culina reported seeing Joao's tabari in the jungle, searching for his hammock, that is, for a proper burial. At night the barking of dogs was taken as a sign that his tabari wandered through the village, looking for food and other tabari, not realizing that he was actually dead. Following the night on which Katore's tabari conducted to the nami budi, it was said that the jaguar tokorime had eaten Joao tabari, and that it would trouble the village no more" (Pollock, 1985, p. 96). 
Jodsino: Quando eu cheguei a casa eu não falei com ninguém [depois da caçada mal-sucedida e do choque de sua cabeça com o macaco-preto]. Fiquei no posto de saúde. Assarina [sua esposa] atou a rede para mim e eu fiquei deitado.

Eu fui para o polo-base. Mas eu só fiquei lá no polo mesmo. Eu demorei quatro meses para ficar bom. Eu ficava tonto e só na rede. Quase eu ficava doido.

Eu: E agora, você vai morar aonde, Jodsino?

Jodsino: Vou morar agora na aldeia Boca do Jaci. Lá eu tenho casa. Lá tem peixe: pacu e piau. Mas pra comer matrinxã eu tenho que ir até aldeia Mapiranga. Só para passear eu vou ao Mapiranga. Eu tenho casa lá. Vou só para passar uns dias, uma semana, depois eu subo [viaja no sentido rio acima, rumo à aldeia Boca do Jaci]. Depois eu vou para Carauari e passo duas semanas, três semanas, e volto. Eu tenho casa lá [em Carauari]. Agora roçado eu não fiz [em Carauari], porque eu passei o ano aqui e não plantei minha roça. Ano passado eu plantei lá.

Eu: Assarina, você acha melhor morar na aldeia Mapiranga ou na aldeia Boca do Jaci [Juruapuca]?

Assarina: No Mapiranga era bom porque tinha muito peixe, mas no Jaci é bom porque tem muita fruta, muito açaí. Só que no Jaci só tem peixe pequeno.

Jodsino: Negócio é bebida. Se não tem bebida [bebidas alcoólicas], se não comprar nenhuma, é bom pra morar. A gente faz ajie [ritual, festa] e poho ppejene [caiçuma de macaxeira]. Eu tenho casa. Mas não tem casa de saúde [posto de saúde]. Ontem procuraram meu nome, mas não estava. Estava tudo na aldeia Mapiranga [na lista do controle de doenças do DSEI-MRSA polo-base Cumaru]. Eu perguntei por que meu nome não estava. A enfermeira disse que é porque eu já saí. Ela disse: "Tu mora pra acolá, tu mora pra ali. Por isso teu nome não está na lista." Eu quero falar com conselheiro do DSEI. (Conversa gravada na casa de Jodsino, cidade de Juruá, dezembro 2015).

No dia $1^{\circ}$ de outubro de 2016, as famílias de Jodsino, Huadsorini, Ibora e Isamani foram passar o dia no Juruapuca. Jodsino me convidou para ir com eles. A viagem foi realizada usando um motor rabeta. Como era época de verão, a boca do lago Juruapuca estava seca e a correnteza, muito forte. Os homens foram de canoa e nós, mulheres e crianças, fomos caminhando pelas margens do sangradouro, no meio do capim. Ao chegarmos mais perto do lago retornamos à canoa. Depois Jodsino nos 
deixou às margens do igarapé Branco. Os homens foram pescar no lago Juruapuca e nós ficamos conversando. Foi lá que Assarina ${ }^{18}$ contou para seus filhos e netos as histórias antigas do lugar, como, por exemplo, quando a onça atacou seu tio Dsomami - uma onça que tinha olhos de fogo e parecia um tocorime (ser extra-humano). ${ }^{19}$ Contou também quando os Kulina moravam lá e trabalhavam extraindo madeiras para o patrão Citone.

Logo depois os homens retornaram com os peixes e continuamos a viagem. Ao pararmos local da antiga aldeia Juruapuca, Jodsino me mostrou com entusiasmo o local do terreiro, das casas, dos roçados. Entre as plantações identificou arbustos de cuia e de urucum plantados por seu pai. Percebi que no local há muitas palmeiras de açaí e de pupunha. Perguntei a Jodsino se eram plantações deles, ele disse que era plantação dos brancos que haviam morado no local depois que eles saíram. Somente depois concluí que a finalidade da viagem ao Juruapuca, naquele dia, era que Jodsino me apresentasse o território.

Jodsino [apontando]: Por aqui tinha casa e por aqui também. Mais à frente estava o local de trabalho, a casa de farinha do Dorome.

Eu: Dorome também morou aqui?

Jodsino: Sim, ele morou. Pra ali ficava a casa do Dorome, do Manezin [Jodso] e do Dsomami. Morava todo mundo aqui. Do outro lado desse igarapé aqui, tem uma capoeira muito grande, um roçado velho dos Madijadeni [do pessoal].

Eu: Aonde está o cemitério dos Madija?

Jodsino: Pra lá, mais longe, lá para o outro lado, mais longe da aldeia.

Eu: Quem foi enterrado aqui?

18 Assarina Kulina ficou órfã quando era criança. Ela e seus dois irmãos Jinasso e Samoja (falecido) são filhos adotivos de Dsomami. Assarina exerce grande liderança na TI Kumaru, na cidade de Juruá e no território Juruapuca.

19 Lorrain afirma que para os Kulina os seres humanos têm três espíritos: a sombra da pessoa projetada sobre a terra, que vai para o submundo após a morte; a sombra ou reflexo da pessoa sobre a água, que vai para o mundo superior após a morte e é devorada por maji (sol); e um espírito que vagueia no mundo após a morte. Todos os três são chamados tocorime. Contudo, Lorrain alerta que traduzir o termo tocorime como "alma" ("espírito") não é adequado, pois um tocorime é uma entidade concreta e integral. Os Kulina chamam de tocorime os espíritos dos animais, bem como uma série de outros seres sobrenaturais (Lorrain, 1994, p. 38). 
Jodsino: Aqui está enterrado o velho Toquiha. ${ }^{20}$

Assarina: Filho, olha se não tem fruto de tucumã no chão. Mais lá na frente tem o roçado velho dos Madija [Assarina apontando].

Jodsino: Aqui ficava o grande terreiro da aldeia. Próximo ao terreiro moravam Daora, Najora, e o pai do Najora, o Equeno. As casas iam até mais na frente. Eram bem 20 casas.

Eu: Quem foi primeiro para o Cumaru, foi Dorome?

Jodsino: Sim, ele foi para o Cumaru e papai ficou ainda aqui, parece que 1988 até 1990. Aqui tinha um terreiro muito grande.

Eu: E aquele pé de urucum? É plantação de branco ou de Madija?

Jodsino: Não é plantação de branco. É plantação de Madija, plantação antiga de Madija.

Jodsino: Olha pra cá! Estes pés de bacaba são de Madija. Aqui tinha casa. Madija fazia vinho-suco de bacaba, jogava os caroços para cá e nasceram. As palmeiras de açaí não são plantações de Madija, são plantações de carihua [não indígena]. Bacaba do pai do Rohuidsi, do Majora. Mas ali ficava a casa do Rohuidsi, tá vendo? A casa de farinha deles ficava mais pra lá.

Eu: Há frutos de urucum?

Jodsineia: Tem sim!

Jodsino: Vai colher! (Transcrição do vídeo, feito por mim, durante a visita ao território Juruapuca com a família de Jodsino, outubro de 2016).

Para Bartolomé os novos confrontos entre Estado e povos originários têm bases na conceitualização diversa dos espaços. Para os estados nacionais, o território é classificado como domínio e como meio de produção. No entanto, para os povos originários o território possui distintas classificações: os espaços são caminhos, locais de trabalho, de residência, ou locais onde estão os mortos. É dessa forma que o território étnico se configura como uma geografia mítica. ${ }^{21}$

20 No cemitério do Juruapuca estão sepultados o pai do Sajini (Toquiha), o filho do Nomiha, o filho do Cobi, o filho da Joriha e o filho da Caido. O cemitério está localizado em um local da floresta, com muitas árvores, mas os Kulina o sabem identificar.

21 Referências tomadas a partir de anotações feitas por mim no "Colóquio Saberes e Ciência Plural: Pluralismo e interculturalidad, las territorialidades confrontadas en America Latina”, Miguel Alberto Bartolomé (Instituto Nacional de Antropologia e História - INAH Oxaca, México), INCT Brasil Plural/PPGAS/UFAM, 24 a 26 de novembro de 2014. 
Isso ficou claro durante a visita ao Juruapuca. Na ocasião Jodsino nos contou a história da origem de algumas variedades de plantas cultivadas no roçado. ${ }^{22}$

Jodsino: Quando eu tinha sete anos meu pai contava histórias antigas e eu aprendia. Ele contava até 11 da noite. Quando era três da manhã ele acordava e começava a contar de novo até amanhecer. Eu tenho histórias na minha cabeça que aprendi de meu pai.

Assarina: Agora o Jodsino está contando histórias de noite.

Jodsino: Vou contar história antiga dos primeiros roçados [ou de onde vieram as plantas], a história da primeira macaxeira.

[Jodsino deixou de falar em português e começou a falar somente em Kulina]:

Huidsajacca huima

Maittaccadsama pohopa nami bodicca poho.

Bama mitta tocomacosani nade. Bama dsoppineje.

Tohuairo pohope, nami bodicca poho nade.

Dsoppineje aje cassihuaja, cassihuja, cassihuaja nami bodi tojajari. Canidsape poho edeni ajimanehe ccanijaro nade. Tohuairo poho, ajimanani. Abi atti, qqui, poho.

Neraha tattidsape anini. ajidsape nohuerani. Poho jaboni moppo. Ajimanani.

Maidsocape denima. Napijaro aji neraha jabono ajimanani nade.

Ssina nami bodicca.

Tohuairo poho nami bodicca najaro nade. Tocorime onini.

Inacajijaro ajijaro pohope tohuairo poho deja najari nadeja.

Badocca poho aji.

Jadani naqui.

Issini, canorara naqui nami bodicca.

Issini nohue, canorara nohueraha.

Tocorime, dsoppineje pohua huidsajara tabota tabotanajari.

Tomaittani Bama iccanajaro nade.

22 Apesar de usar a expressão "história da origem de algumas variedades de plantas", a inclusão dessa narrativa, nesse momento, tem a intenção de apresentar " $[. .$.$] uma tentativa de reflexão do$ nativo sobre seu próprio universo" em um momento de retomada de um território (Pacheco de Oliveira, 1988, p. 107). 
Huattitajari nade ajimanajaro ticca jimanani nitide, bononi bicatani appaiani dainani. Dsoppineje appa.

Ohuadsa ppatodsani huajine, ajimanani, anini nitide? Anini. Idsamassa joppacajonani huajine.

Manaco tomaittanipe dsoppinejedsa huaitajari. Ajijaro paje.

Pohua cajonani ahuanani. Issini nemani ccajona. Ppaidsajaro.

Onihi anini nitide, jadani? Canorara nitideja. Canorara huahuanani ajimanaha. Bama cainajaro canorara ssajaissi ssajaitajaro.

Nidsa carihuacca aje: ossara, banana prata, bare, maccoco.

Ajijarope nami bodicca tocorime toccamacossani najaro.

Maittaccadsamacca huima nahui nade.

Majonana aje abari nade. Majonana carihuacca. Majonana quiriro nami bodicca. Dsahuiri, dsahuiri najaro. Majonana carihuacca jicajerahui. Majonana quiriro dsahuiri dsahuiri madijadeniccape.

Maidsoca naqui carihuacca. Maittaccadsama nohuerani paridsa. Poho ppejene nani.

Bija dsarahua, dsamacca. Naturalcca bija.

Assarina: Anide. Gaviazinhodsape anide. Ijipade. Edeni pina bija, pina bija plantado. Cahuarini bicatade. Pina cahuarini abadsa tijipani.

Jodsino: Podsanani mamoredsa bica. Cahuarini bica.

Badocca poho rabo ajimanani, ppainajaro, morotajaro.

Simaca edeni ahuanade, madija mattaiccadsamacca jijipa, cahuari, ppodsanani daneraha. Ajidsape nohuerani, tattinidsape anini tohui. Gaviazinhodsa anini, abadsape ojipani.

Maittaccadsama nohuerani jadani, nami bodicca.

Jarissi naqui nami bodicca.

Dsoppinenje nani bacco, huatti, pohuadsa ohaha nani da, eccamaccossani, huidsajadsa ppainajaro. Huada ssihuaja, tomaittani tocorime huatti temaccossani, jaressi ecamacossani.

Canorara ecamaccossani. Ssina manaco. Ssina ajimanani, jojo bedidsa, da toccanidsa, cacamacossani.

Tapa naqui anini madijadenicca tapa. Potatade nocco. Dacotade madijadenicca tapa. Ajidsape nohuerani tapa. Carihuacca tapa anihui. Tattinidsa aninhui madijadenicca tapa.

Maittaccadsamacca huima anini sibatade. 
Abipa boronidsa, ejedeni jatadsa Juruapucadsa huati huati nana nade: ohua, Rohuidsi, badsima, imejocohi, ejedeni jataji boronidsa huati huatinana nade. Huati nahui ajimanadsa comessa neraha pina onze jana huadahui tohui, dsome. (Conversa gravada com Jodsino e Assarina, Juruapuca, outubro de 2016).

[Tradução]: ${ }^{23}$

História do roçado

Antigamente a macaxeira veio de debaixo do chão [nami bodi, patamar subterrâneo]. ${ }^{24}$ Bama desceu para comprar [ou para pedir]. Bama era pajé.

A macaxeira era do inhambu, que cultivava macaxeira no nami bodi [patamar subterrâneo].

O pajé ficou lá embaixo até amanhecer. Ficou outro amanhecer, outro amanhecer [três dias]. Quando ele voltou, ele trouxe um pedaço de maniva desse tamanho [mostrando tamanho do pedaço com as mãos]. A macaxeira cultivada pelo inhambu era desse tamanho. Meu pai falou:

- Olha, macaxeira!

Aqui não tem essa variedade de macaxeira, mas os Madija lá de cima [Alto Juruá] ainda cultivam. Essa macaxeira tem a raiz bem branca. A mandioca veio depois. A raiz dessa macaxeira cresce muito. O rapé veio [é] do nami bodi [patamar subterrâneo]. Inhambu cultiva macaxeira no nami bodi [patamar subterrâneo]. Esse é o nome do tocorime [ser que habita o patamar subterrâneo]. Tohuairo [forma de inhambu] é nome do tocorime que mora no nami bodi. Quando o pajé veio de lá debaixo, ele trouxe para nós essa macaxeira, que é cultivada pelo Tohuairo. O tipo de macaxeira que conhecemos como macaxeira de veado é daqui de cima, ou daqui de fora. Assim também [acontece com] as bananas. Issini e canorara

23 Tradução feita por mim. O meu conhecimento da língua é fruto da relação de mais de 20 anos com os Kulina no Baixo Juruá, iniciada nos anos 1990 no Cimi e, recentemente, em pesquisas acadêmicas dos cursos de mestrado e doutorado do Programa em Pós-Graduação em Antropologia Social da Universidade Federal do Amazonas.

24 Plataforma subterrânea que compõe o cosmos, ou: "Below the palpable earth known to all humans lies the world called nami budi is literarly 'underground.' The nami budi is nearly identical to the know earth, composed of forest, rivers, animals, and villages, it is the realm of the dead and the not-yet-born, which form part of the general class of spirits known as tokorime, spirits who live in a manner similar to that of terrestrial humans and animals" (Pollock, 1985, p. 49). 
[variedades de bananas cultivadas pelos Kulina ${ }^{25}$ ] são do nami bodi. Não tínhamos [não cultivávamos] issini e nem canorara. O tocorime e o pajé Bama trabalharam e fizeram um roçado no nami bodi. À tardezinha o pajé Bama voltou. Então ele falou:

- O fruto-banana parece gostoso, acho que dá para comer.

O pajé comeu. E pediu:

- Eu quero essa banana para plantar. Uma muda de banana assim. Será que tem?

- Sim, tem. Amanhã você vem buscar.

Em contrapartida, à tarde o tocorime chamou o pajé:

- Aqui está [a muda de banana].

Quando o pajé voltou nos trouxe a muda de banana. Trouxe uma muda de banana issini desse tamanho [fazendo gesto com as mãos] para plantar. Nós plantamos [ou nós passamos a cultivar].

- Há outro tipo de banana que veio do nami bodi? [Ele pergunta e ele mesmo responde]

- Sim, há outra variedade de banana que veio do nami bodi: a canorara. Sobre ela vou falar.

Bama trouxe a [variedade] canorara. Espera! As variedades de banana dos não indígenas são: ossara, banana-prata, banana-comprida e banana-vermelha. As outras variedades de banana são dos tocorime, eram cultivadas lá embaixo [nami bodi] e agora subiram [são cultivadas nesse patamar]. São assim as histórias antigas.

A cana-de-açúcar é daqui de cima. A cana-de-açúcar é dos brancos. Mas a cana-de-açúcar que chamamos de quiriro é do nami bodi. Ela é listrada, malhada, tem pinta. Os brancos possuem muitas variedades de cana-de-açúcar. A cana-de-açúcar quiriro, dos Madija, é bem malhada [listrada ou com pinta]. A mandioca também é um cultivo dos brancos. Antigamente não existia farinha. Havia caiçuma de macaxeira. O cará dsarahua é da floresta. É um cará natural.

Assarina: Tem esse cará na aldeia Gaviãozinho. Nós comemos esse cará quando estávamos na aldeia Gaviãozinho. A planta dele parece a planta de cará plantado. Quando a gente cozinha ele fica gostoso. É bom para comer com peixe. Jodsino: Cozinha o cará. E é muito bom para comer com matrinxã assado.

25 Preferi conservar o nome das variedades de macaxeira, banana, batata e abacaxi, por não ter feito um trabalho de identificação das mesmas. 
A macaxeira de veado tem uma raiz desse tamanho [fazendo gesto com as mãos]. Simaca é outra variedade de macaxeira antiga dos Madija. É boa para comer cozida, não dá para comê-la assada. Aqui não tem. No Alto Juruá tem. Na aldeia Gaviãozinho tem, foi lá que eu comi com peixe.

Antigamente não existiam bananas, elas estavam [são] no patamar subterrâneo. A batata também é do patamar subterrâneo. O pajé chegou lá embaixo e falou. O pajé pediu ao tocorime a batata. Passou um dia, amanheceu. Eles [tocorime] deram batata para o pajé, então ele subiu com a batata e a plantou no roçado. Banana da variedade canorara também veio do patamar subterrâneo e subiu. O pajé deu rapé aos tocorime e em troca conseguiu as variedades de plantas do patamar subterrâneo. O pajé deu bastante rapé ao tocorime e por isso conseguiu as plantas.

O milho também. Existe o milho dos Madija. O milho dos Madija tem caroço grande e é muito mole para cozinhar, e para comer o milho. Aqui não tem milho dos Madija [ou não temos sementes do milho dos Madija na região do Baixo Juruá]. Aqui só tem milho de não indígenas. No Alto Juruá tem milho de Madija. Há muitas histórias antigas. Meu pai contava todas essas histórias quando morávamos na aldeia Juruapuca e éramos crianças: eu e Rohuidsi, todos. Os adultos e as crianças sentavam no terreiro e ficavam ouvindo histórias antigas. Os velhos começavam a contar histórias à tardezinha. Eles só paravam de contar histórias por volta das 11 horas da noite, quando íamos dormir.

Nessa grande narrativa - que versa sobre o surgimento de algumas variedades de plantas cultivadas - podemos observar como os Kulina ressignificam aspectos culturais como formas de enfrentar o processo de territorialização atual. Podemos observar também a importância dos pajés, o conhecimento e o aprendizado das histórias antigas.

Para Lorrain (1994) ${ }^{26}$ os grandes líderes do passado são lembrados por serem plantadores com extensos roçados e produtos generosamente compartilhados em contextos rituais. Os grandes líderes são guerreiros, pajés que protegem seu grupo contra as ameaças externas, caçadores e doadores de comida. Quando há conflito e o líder não pode articular um consenso, apenas pequenos roçados

26 Lorrain (1994) desenvolveu sua pesquisa entre os Kulina do Médio Juruá (aldeia Terra Nova). 
são feitos, ou simplesmente não são feitos. Como resultado toda a aldeia passa fome, iniciando uma série sucessiva de migrações. Fluxos populacionais são comuns, motivados não apenas pela insuficiência ou ausência de mandioca, mas também pelos conflitos ou assassinatos. Há casos em que seções inteiras podem abruptamente mudar para outras aldeias.

Dentro dessa mesma linha de análise, Pollock afirma que os rios e igarapés são rotas para o mundo subterrâneo dos mortos. E os roçados se tornam rotas para o mundo subterrâneo (nami bodi) quando mortos são sepultados no local (Pollock, 1985, p. 38). Nesse sentido, podemos entender a importância do território Juruapuca para os Kulina: o mesmo não é apenas um local de morada dos vivos, mas uma rota privilegiada de acesso ao mundo subterrâneo (nami bodi), pois possui roçados antigos onde várias pessoas foram sepultadas.

Nesse processo de reocupação do território Juruapuca, os Kulina solicitaram a minha contribuição. Acreditam que eu poderia mediar uma relação mais diplomática com o ICMBio e os moradores da Resex Baixo Juruá na busca de uma gestão compartilhada do território. Solicitaram também acesso a documentação que comprovasse a presença deles no território Juruapuca antes da criação da Resex Baixo Juruá. Assim, com apoio da equipe do Conselho Indigenista Missionário (Cimi-Tefé), empreendi uma pesquisa da documentação que consta nos arquivos do Cimi.

As narrativas a seguir não têm a função de "comprovar" a veracidade histórica das narrativas contadas pelos Kulina: constituem outra forma de discurso que aborda a relação histórica de pertença do território Juruapuca aos Kulina. A narrativa não partirá de relatos orais, mas de registros escritos feitos pelas equipes indigenistas do Cimi que trabalharam no local entre os anos de 1985 e 1990.

No documento que tem como título "Relatório de Educação junto aos Kulina na região do Baixo Juruá, município de Caitaú, aldeia Vila Nova - Juruapuca (igarapé Grande), período: 1986 a 1989", a equipe da pastoral indigenista (Cimi-Tefé) era formada por Antônio José Mota Bentes e Iza Maria Castro dos Santos. Eles relatam que foram convidados a trabalhar na Prelazia de Tefé em janeiro de 1985 e aceitaram o convite em fevereiro de 1985. Depois de fazerem visitas aos indígenas nos rios Japurá, Xeruã e em Uati-Paraná (Fonte Boa, AM) optaram por desenvolver um trabalho mais sistemático junto aos Kulina no Baixo Juruá: "Foi durante este primeiro contato que surgiu através do pedido 
dos próprios índios da aldeia de Juruapuca que começássemos o processo escolar na área" (Bentes; Santos, 1990a, p. 1). Nesse relatório a equipe indigenista deixa claro que o processo de educação escolar aconteceu apenas na aldeia do Juruapuca, mas ressaltam que na região do Baixo Juruá existiam mais duas aldeias: aldeia Matatibem (no rio Eré, próximo à cidade de Carauari) e uma aldeia no igarapé da Macaca (atualmente Terra Indígena Kumaru do Lago Ualá). A população total das três aldeias era de 287 pessoas, entre adultos e crianças.

Em um documento anterior, no qual a equipe indigenista registra aspectos socioculturais dos Kulina, relatam como principal característica seus constantes deslocamentos: "Os Kulina aqui do Juruapuca, entre outros, são bastantes conhecidos pelos regionais e ribeirinhos, por percorrerem esta região em peregrinação de lugar em lugar. Entre Juruá e Jutaí estes índios percorrem e buscam uma forma de sobrevivência" (Bentes; Santos, 1985a). Quando a equipe começou a trabalhar com os Kulina os mesmos estavam retornando ao local, pois anos antes haviam sido transferidos para o rio Andirá (território localizado acima da cidade de Juruá). A transferência trata-se de um acordo firmado entre a prefeitura de Juruá (antiga Caitaú) e a Funai. Esses órgãos respaldaram o acordo a partir dos problemas enfrentados pelos Kulina devido ao contato estreito com a população da cidade: prostituição e alcoolização.

Jodsino: Funai chegou e queria falar com o prefeito pra prefeito levar Madija lá para dentro do Andirá [igarapé]. Levaram todos os Madija lá para dentro do Andirá.

Primeiro foi só a família do papai. Foi chegando, chegando, chegando... Madija com família todinha: Dorome, Majoro e Tomahua [pai do Joaquim]. Toda família dele já vai chegando. Primeiro chegou meu tio Majora [pai do Rohuidsi] e Equene. O Joji morreu lá no Requeque [Vai-quem-quer]. Joji é irmão [ou primo paralelo] do Equene. Moravam lá todas essas famílias. Não tinha aldeia, não tinha nada, não tinha professor, não tinha Funai, não tem nada. Então chegou Funai aqui e conversou com papai e falou com o Raimundo Batalha, conseguiu motor [barco]. Nome da Funai era José Nobre.

Ele levou Madija lá para o Andirá, quando fez um ano os Madija voltaram pra cá, pra Caitaú. Pegaram malária, tinha muita malária no Andirá, quase que o pessoal todo morre. Funai voltou de novo, pegaram um motor e levaram Madija daqui, lá para aldeia de novo. Madija fizeram canoa e já vieram baixando pra cá. 
Andirá é muito longe. Sai daqui e tu dorme abaixo da boca do Andirá.

Lá é terra do indígena, tem placa ainda. Terra de branco é só daqui pra baixo. Mas ninguém mora no Andirá. É muito longe. Tem placa aqui embaixo e tem placa lá em cima. (Conversa gravada na casa do Jodsino, cidade de Juruá, dezembro de 2015).

Os Kulina permaneceram na aldeia, no rio Andirá, cerca de dois a três anos. Em outubro de 1985, existiam 31 famílias Kulina morando no igarapé Grande (aldeia Juruapuca), totalizando 147 índios (Bentes; Santos, 1985a).

Estes índios há muito tempo atrás viveram nas cabeceiras do igarapé Grande, mais tarde em decorrência do contato com os kariú, de Caitaú, mudaram-se para o rio Andirá (afluente do rio Juruá, acima de Caitaú) [...] e os constantes casos de malária e tuberculose fizeram com que eles se mudassem do Andirá e voltassem para o lugar de onde tinham partido. Hoje esses Kulina vivem aqui em Juruapuca, mas propriamente no Igarapé Grande. Outros por sua vez foram para o Macaco e no Vai-quem-quer. (Bentes; Santos 1985a).

O objetivo do trabalho do Cimi, de 1985 a 1990, era a conquista da terra, promovendo o levantamento fundiário da área onde os Kulina se encontravam, a discussão de um limite para uma proposta de demarcação, a formação de lideranças, a construção de escolas alternativas e a alfabetização como instrumento de autodefesa. Contudo, a equipe relata: "O álcool tem sido um problema de toda a aldeia. Os comerciantes de Caitaú fornecem bebidas alcoólicas para os índios em troca de galinhas, carne de caça, peixe, paneiros, etc." (Bentes; Santos, 1985a).

Em 1985 havia, na aldeia Juruapuca, oito roçados. Os Kulina pescavam no igarapé Grande e no lago Juruapuca (matrinxã, piranha, piau, pirapitinga, surubim, pacu, pirarucu e bodó). Trabalhavam na extração de látex (no inverno e no verão), que era vendido em Caitaú (cidade de Juruá) para o patrão Antônio Napoleão (a seis mil cruzeiros o quilo). A equipe indigenista salienta ainda que na área do Juruapuca havia sempre presença de madeireiros, principalmente Citone Medeiros, “[...] que há vários anos tira madeira desta região utilizando a mão de obra dos índios" (Bentes; Santos, 1985b). Nesse ano, a escola da aldeia Juruapuca era de palha e paxiúba, construída pelos próprios indígenas. Mas 
os Kulina tiveram uma escola construída pela prefeitura na aldeia Andirá. A escola na aldeia Andirá funcionou por três meses com aulas ministradas por uma professora não índia, porém, como a desistência da professora, a escola deixou de funcionar (Bentes; Santos, 1985b).

Em um levantamento demográfico realizado em 1985, a equipe indigenista constata que a aldeia Juruapuca possui 31 famílias e 149 pessoas, e descreve com maior precisão a localização das aldeias Kulina no Baixo Juruá:

Os grupos de Kulina do qual nos referimos estão localizados no percurso do Baixo Juruá, mais propriamente em seus afluentes. Um dos grupos do Juruá está localizado no afluente de nome Juruapuca. Outro grupo Kulina está localizado mais abaixo no Juruá numa colocação de nome Vai-quem-quer. Ainda no Juruá, mais abaixo do Vai-quem-quer, encontra-se outro grupo de Kulina localizados num seringal de nome "Cumaru" dentro de um igarapé de nome Macaco. A outra parte dos Kulina está localizada de modo dispersa nas confluências do rio Jutaí. Estes grupos que nos referimos denominam-se "biro madija", gente dos tucanos (tucano é um pássaro da região²7). (Bentes; Santos, 1985b).

Em uma proposta de projeto a equipe indigenista descreve a situação da terra. Ressalta a existência de conflitos fundiários e as "constantes migrações" dos Kulina. Essas migrações seriam decorrentes de "conflitos entre brancos e índios", ou entre os próprios índios:

Em decorrência desse fato os índios são praticamente odiados em toda a região. São tidos como os piores dentre todas as nações indígenas - mal [sic] caráter, ladrão, preguiçoso, valente traiçoeiro e outras acusações são comuns na boca de seringalistas, políticos e mesmo ribeirinhos, quando se referem aos índios. (Bentes; Santos, 1985b).

Em maio de 1989, aconteceu um evento que acabou desencadeando uma série de conflitos que desgastou a organização interna da aldeia Juruapuca e consequentemente provocou uma grande dispersão: dois Kulina foram feridos

27 Observação feita pelos autores. 
gravemente e tiveram que ser encaminhados para tratamento em Tefé. As pessoas envolvidas no conflito estavam embriagadas. As mesmas haviam consumido bebida alcoólica ao participarem da festa do santo da cidade de Caitaú-Juruá. Em decorrência desse conflito, algumas famílias se mudaram para a aldeia Cumaru (igarapé da Macaca-TI Kumaru). Para a equipe indigenista os conflitos e rupturas, na organização interna da aldeia, se acentuaram com a presença de uma base de pesquisa da Petrobras próximo à aldeia Juruapuca:

Da última vez, por exemplo, em que a empresa esteve na área o descaso aos índios chegou ao ponto de a empresa fazer até pista de pouso ao lado da aldeia, permitindo um relacionamento direto entre os índios e os peões, onde o problema maior é a prostituição das índias, a introdução de mais álcool na aldeia e o pior de tudo, a contaminação aos índios de doenças altamente transmissíveis. (Bentes; Santos, 1989, p. 6).

No relatório de atividades desenvolvidas na aldeia Juruapuca, em dezembro de 1989, a equipe descreveu a situação dos Kulina e a possibilidade de "subida" (deslocamento) de 14 famílias da aldeia Juruapuca para a aldeia Matatibem, no rio Eré (Bentes; Santos, 1990b). Os Kulina sugeriram que a equipe indigenista se deslocasse com eles ao Eré para continuar os trabalhos de educação escolar. Além disso, a equipe ressaltava que a prostituição e a mistura dos Kulina com os brancos tinha se intensificado. No novo levantamento populacional, realizado no segundo semestre de 1989, a equipe indigenista registrou apenas a presença de seis famílias na aldeia Juruapuca. Por fim, constatou-se que houve um grande deslocamento de famílias após o conflito no qual dois Kulina ficaram gravemente feridos. Tudo isso, junto com outros fatores agregados - como a presença da Petrobras na área - acabou provocando o esvaziamento populacional da aldeia Juruapuca.

Porém, em registros mais antigos, é possível identificarmos a presença Kulina na região do Baixo Juruá, na época de auge da exploração da borracha. Tastevin registra a presença de Kulina ("Colinas") no igarapé da Macaca (atualmente localizado dentro da TI Kumaru do Lago Ualá) e no seringal Juruapuca (território Juruapuca, localizado à jusante da atual cidade de Juruá) (Tastevin, 1982, p. 32 apud Faulhaber, 1994, p. 7). 
Através da análise das narrativas e dos registros escritos é possível perceber o confronto de diferentes concepções de território. Na verdade, uma sobreposição de territorialidades, na qual os Kulina representam a parte menos ouvida na implantação das políticas públicas. Nesse sentido Alban Bensa - ao refletir a relação entre as elites e a população local de Paris - apresenta um exemplo que se aplica à forma como foi concebida a Resex Baixo Juruá, sem a participação dos Kulina:

Por ejemplo, los proyectos relativos a la protección del patrimonio cultural, de montañas, litorales, ríos, son frecuentemente dispositivos de gran alambicamiento y basados en una concepción etérea de paisaje, y muy raramente toman en cuenta las prácticas efectivas de las poblaciones locales, agricultores, pescadores, etc. (Bensa, 2015, p. 61).

Bensa alerta ainda que a etnografia deve oferecer a possibilidade de escutar e fazer valer o ponto de vista legítimo daqueles que são poucos consultados e ouvidos (Bensa, 2015, p. 61).

Assim, a título de conclusão, é possível perceber o processo de territorialização deflagrado pela instância política estatal e arbitrária - que classifica indivíduos e grupos a limites geográficos determinados - mas também a forma como os Kulina repensam e formam uma coletividade étnica que se distingue das demais (Pacheco de Oliveira, 2002, p. 278). Falar do passado é, portanto, uma forma de reconstruir o presente, e assim refazer o projeto político.

Desenvolvi esta análise dentro de uma conexão entre história e memória, não a partir de uma visão historicista dos acontecimentos, mas sim observando como as imagens do passado, magicamente fortalecidas, irrompem em um momento de perigo (Taussig, 1993, p. 344-345). Os Kulina associam de forma integrada ações, narrativas e personagens, e constroem uma memória “[...] tecida pelos próprios atores sociais em diferentes situações, trazendo para seus novos usos muitos sentidos infusos em usos anteriores" (Pacheco de Oliveira, 2016, p. 26).

Por fim, a análise partiu da concepção de território como elemento fundamental na constituição dos Kulina como um grupo étnico. Compreender o rio Juruá como um grande território Kulina foi a chave para analisar a reocupação dos Kulina do território Juruapuca. Narrativas variadas apontam para 
o movimento histórico de expulsão e retorno dos Kulina ao local atualmente reconhecido como Resex. Parti do desafio de levar a sério a fala Kulina, quando afirmam que "somos jidsama madija [queixadas madija]", e declaram que seus deslocamentos vão ao encontro de uma família, de um arbusto ritualístico ou de um roçado antigo. Descobri que não é somente a presença dos vivos no território Juruapuca que o converte em um território Kulina, pois a maioria das pessoas vive em constantes deslocamentos - com famílias que têm casas na cidade e em distintas aldeias. Apreendi que a concepção de território Kulina mistura o tempo mítico com o tempo atual, pois o território é habitado e guardado pelo rami (ser extra-humano); e o território é a rota de contato com o mundo subterrâneo dos parentes mortos. Dessa forma, o território é entranhado de carga afetiva e simbólica, visto que não separa em locais ou patamares fixos os humanos e os extra-humanos. Assim é possível afirmar que a relação que os Kulina estabelecem com o território não está pautada na noção de propriedade, mas no vínculo com "quem ficou no lugar". Por isso, abrir mão desses lugares é abrir mão dos vínculos entre humanos e não humanos. O descuido com esses territórios implica punições de outra ordem, não previstas nos procedimentos de controle do Estado.

\section{Referências}

AMORIM, G. Os coletivos madija e o ritual do Ajie: relações de alteridade entre os Kulina no Baixo Juruá. 2014. Dissertação (Mestrado em Antropologia Social) - Instituto de Ciências Humanas e Letras, Universidade Federal do Amazonas, Manaus, 2014.

BENSA, A. Después de Lévi-Strauss: por uma antropología de escala humana: una conversación con Bertrand Richard/Alban Bensa. Trad. Liliana Padilha Villagómez. México: Fondo de Cultura Económica, 2015. (Colección Umbrales).

BENTES, A. J.; SANTOS, I. M. Índios Kulina: coleção de dados. Tefé: Conselho Indigenista Missionário, 1985a. Sem paginação.

BENTES, A. J.; SANTOS, I. M. Projeto povo Kulina. Tefé: Conselho Indigenista Missionário, 1985b. Sem paginação.

BENTES, A. J.; SANTOS, I. M. Relatório de atividades janeiro a julho de 1989: Aldeia Juruapuca. Tefé: Conselho Indigenista Missionário, 1989. 
BENTES, A. J.; SANTOS, I. M. Relatório de educação junto aos Kulina na região do Baixo Juruá: município de Caetaú, aldeia Vila Nova - Juruapuca (igarapé Grande): período: 1986 a 1989. Tefé: Conselho Indigenista Missionário, 1990a.

BENTES, A. J.; SANTOS, I. M. Relatório de atividades: período: dezembro de 1989. Aldeia Juruapuca (Vila Nova). Tefé: Conselho Indigenista Missionário, 1990b.

CABRAL DE OLIVEIRA, J. Mundos de roças e florestas. Boletim do Museu Paraense Emílio Goeldi: Ciências Humanas, v. 11, n. 1, p. 115-131, jan./abr. 2016.

FAULHABER, P. Relatório de identificação e delimitação da A. I. Cumaru (Kulina/Madija). Brasília: Fundação Nacional do Índio, 1994.

GORDON, F. Os Kulina do Sudoeste Amazônico: história e socialidade. 2006. Dissertação (Mestrado em Antropologia Social) - Museu Nacional, Universidade Federal do Rio de Janeiro, Rio de Janeiro, 2006.

LORRAIN, C. Making ancestors: the symbolism, economics and politics of gender among the Kulina of Southwest Amazonia (Brazil). 1994. Tese (Doutorado em Antropologia Social) - University of Cambridge, Cambridge, 1994.

MARCUS, G. Etnografía en/del sistema mundo. El surgimiento de la etnografía multilocal. Alteridades, v. 11, n. 22, p. 111-127, 2001.

PACHECO DE OLIVEIRA, J. O caboclo e o brabo: notas sobre duas modalidades de força de trabalho na expansão da fronteira amazônica no século XIX. Encontros com a Civilização Brasileira, v. 11, p. 101-147, 1978.

PACHECO DE OLIVEIRA, J. O nosso governo: os Ticuna e o regime tutelar. São Paulo: Marco Zero: CNPq, 1988.

PACHECO DE OLIVEIRA, J. Ação indigenista e utopia milenarista. As múltiplas faces de um processo de territorialização entre os Ticuna. In: ALBERT, B.; RAMOS, A. R. (org.). Pacificando o branco: cosmologias do contato no Norte-amazônico. São Paulo: Editora Unesp, 2002. p. 277-309.

PACHECO DE OLIVEIRA, J. Ementa da disciplina Antropologia do Território. Manaus: PPGAS-UFAM, 2012.

PACHECO DE OLIVEIRA, J. Nascimento do Brasil e outros ensaios: "pacificação", regime tutelar e formação de alteridades. Rio de Janeiro: Contra Capa, 2016.

POLLOCK, D. Personhood and illness among the Culina of Western Brazil. 1985. PhD Thesis - The University of Rochester, New York, 1985. 
SCHIEL, J. Tronco velho: histórias Apurinã. 2004. Tese (Doutorado em Ciências Sociais) - Instituto de Filosofia e Ciências Humanas, Universidade Estadual de Campinas, Campinas, 2004.

SILVA, D. Música e pessoalidade: por uma antropologia da música entre os Kulina do Alto Purus. 1997. Dissertação (Mestrado em Antropologia Social) - Centro de Filosofia e Ciências Humanas, Universidade Federal de Santa Catarina, Florianópolis, 1997.

SOARES, R.; MOCHIIZAWA, H. O povo Kulina. Manaus: Conselho Indigenista Missionário, 1997.

TAUSSIG, M. Xamanismo, colonialismo e o homem selvagem: um estudo sobre o terror e a cura. São Paulo: Paz e Terra, 1993.

Recebido: 30/09/2019 Aceito: 27/04/2020 | Received: 9/30/2019 Accepted: 4/27/2020 